\title{
Chapter III Philosophical and Epistemological Basis for Building a Quality Online Training Methodology
}

\author{
Antonio Miguel Seoane Pardo \\ Universidad de Salamanca, Spain \\ Francisco José García Peñalvo \\ Universidad de Salamanca, Spain
}

\section{ABSTRACT}

This chapter outlines the problem of laying the groundwork for building a suitable online training methodology. In the first place, it points out that most e-learning initiatives are developed without a defined method or an appropriate strategy. It then critically analyzes the role of the constructivist model in relation to this problem, affirming that this explanatory framework is not a method and describing the problems to which this confusion gives rise. Finally, it proposes a theoretical and epistemological framework of reference for building this methodology based on Greek paideia. The authors propose that the search for a reference model such as the one developed in ancient Greece will allow us to develop a method based on the importance of a teaching profile "different" from traditional academic roles and which we call "tutor." It has many similarities to the figures in charge of monitoring learning both in Homeric epic and Classical Greece. 


\section{INTRODUCTION}

\section{The Failure of E-Learning without a Method}

Online training or e-learning is an authentic revolution in its way of conceiving learning experiences compared to how we thought of them until very recently. It would take too long to list all the changes that have taken place in this new educational modality, which have affected technological elements, communication dynamics, social factors, and new teaching and learning roles, as well as the teaching-learning relationship itself, the value of the contents, and the methodology of the process.

However, despite the euphoria unleashed by online training in recent years, and the fact that the development of tools, training systems, and digital contents has been and still is extraordinary, we can not hide from the fact that there is a certain skepticism or even disappointment when the level of user satisfaction and the outcomes attained in online training are analyzed, if we limit ourselves exclusively to the learning objectives actually attained. What is important in any educational intervention, whatever its type, electronic, at a distance, or face-to-face, is none other than achieving certain learning objectives: the proof of having taught them does not suffice; we need to be sure that they have actually been acquired.

Since e-learning is a type of learning characterized by technological mediation (this is not its only peculiarity, but for the time being we will focus on this aspect) and since what is apparently different with respect to other kinds of training seems to lie in the elements of this mediation, when we analyze the causes of this skepticism (or failure) we usually focus exclusively on the technological factors: the learning environments are not appropriate, the digital contents are not vellestruct, and so forth. Consequently, an $\overline{\overline{\overline{ }}}$ hous amount of material and human re- sources are devoted to perfecting these elements in the hope of improving the learning experience, without our realizing that the solution to the problem lies in another direction.

Logically, the evolution of these technological mediation factors will contribute to improve the context, just as we would improve the learning experience if we renewed the blackboards, the lighting, or the equipment of a classroom in a traditional context. However, we all know that this is not the main thing for achieving quality training. And looking back on our own experience, we all remember that we learned nothing, or very little, from the technical or logistic elements in our schools but we did learn a lot with our good teachers and classmates. Thus, technology must be improved but we can not fall into the trap of only blaming the tool for not being able to reach the desired objectives. Technological mediation in e-learning is precisely that, a medium, and in any case it is a mistake of training strategy not to have had suitable resources, or not to have been capable of adapting ourselves to the means available. The tool is, or we should make it be, as neutral as possible.

All in all, if we study the brief history of elearning we can already speak of "generations" that have marked its development up until now, and whose evolution allows us to predict (assuming that this is possible) where we are going in the future (Seoane, García, Bosom, Fernández, \& Hernández, in $\equiv$. After a first generation marked almost exclusively by the development of technological environments and digital contents, we have moved towards a concern, in recent years, for the e-learning "model" and, consequently, to a concern for the development of implementation strategies and the interoperability of online training environments with an institutional model for the university, the public administration, and business firm. Thus the question of a model of efficiency and quality appears. However, we are witnessing a moment in which a strange paradox is occurring: the greater the technological media- 
tion and the more we implement our systems and improve the environments and training contents with a view to reducing the intervention of the teaching roles, the worse the learning outcomes. It is becoming necessary to go on then towards what we call the "second-advanced generation" in which the importance of the human factor in online training plays a crucial role, not only from the point of view of planning and strategic design, but also, and especially, as an element present in all the stages of the training itinerary. The redefining and centrality of teaching roles in e-learning is the main characteristic of this generational stage, at which many institutions and training initiatives really concerned about quality currently find themselves.

Thus, the cornerstone that will allow us to explain the reason for the disappointment in elearning up until now is the human factor. The great fallacy of technological mediation has consisted of the belief that the mediating role of the classroom teacher would be replaced by technology, when the latter should really be at the service of the teacher, who will still carry on playing the main mediating role in learning.

This mistake, as widespread as it is serious, is the consequence of the transmutation of a training paradigm into one of an "informative" nature. In other words, we can say that underlying this matter there is an enormous confusion between information and education (or training). This situation is not at all new and has come up when analyzing the problems of other "classical" training paradigms, but with online training it has been taken to its ultimate consequences, most likely because of the emergence of the so-called "information society" and information and communication technologies. Their names are accurate enough, but they seem to have subliminally taken on educational aspirations. Indeed, a book, a newspaper, the Internet, or audiovisual material can provide us with information, but never education or training. Education is a specifically human activity that consists, among other things, of the internalization and assumption of specific information with a significant purpose. Thus, as can be seen, education presupposes information, but it is more than that. That is why educational material alone can not "educate." This can only be done by the subject who becomes educated by internalizing, by becoming aware of the value of the contents, by building a meaningful universe within him or herself, or, what is more common, by the mediation of other human beings, who, either individually (with a teacher) or collectively (with a group of students or in the social context itself), contribute to turning information into an educational experience in the mind of the individual. This dichotomy can be compared to what in philosophical terms Aristotle (and later the Aristotelians, specially Thomas Aquinas) called "active intellect" and "passive intellect" (Aristotle, De anima, 430a 10-25; Thomas Aquinas, Summa Theologica, first part, question 79) or to the cognitive distinction between memory and consciousness.

Thus, education is more than information. And if we wish to attain it, we have to go beyond technological mediation and learning objects to speak of human interaction both among students and with teachers, because this is where the success or failure of most educational or training initiatives begins.

Hence, it seems that two major questions still remain to be solved (perhaps because they have not been sufficiently well-defined) before we face the main problem: on the one hand, it is necessary to define a suitable interaction model for online learning, taking advantage of the fact that the tools available make possible new modalities of communication up until now impossible (Seoane et al., in press); on the other hand, not only do we have an unsuitable definition of the teaching attributions and profiles in online training, but they are also being drastically reduced or eliminated. They often end up becoming mere dynamizers and stimulators of learning, as if they were the "cheerleaders" of training. Absurd, right? But absolutely true in many cases. 
But the main problem which our e-learning initiatives often face is the total lack of a suitable method for their development. When we speak of the "second generation" of e-learning we are referring to a strategic approach of the training model required by the entity implementing it. This strategy determines the "what" and the "for what," but only the development of an appropriate methodology will make it possible to develop "how" the pre-established objectives will be achieved.

But is it really true that no methodology for online training has been designed after all these years? Well, an analysis of a good part of the training initiatives and even the specialized literature certainly seems to show this. On the one hand, if we focus on a purely technocentric model, in which the addressee gains access to knowledge and "interacts" with it without any other mediation, there is no method with educational ends and the most we can affirm is whether there has been (or not) a good sequencing and organization of the information and whether or not the student has been able to respond suitably to some test items that prove that this information has been acquired, but not whether real training has taken place. Thus, no matter how much we theorize over these aspects, we will not be going in the right direction in our quest for a training method.

Moreover, if we look at other initiatives based on predominantly vertical human interaction (student-teacher-student), we find that there is no substantial change with respect to certain face-to-face contexts, which leads us to the same problems as in face-to-face teaching without, on the other hand, being able to make good use of the advantages of a completely different interaction and communication model. It would in any case be a similar model to that of tutoring in traditional distance education, which differs considerably from the paradigm we are seeking for e-learning.

Finally, if we analyze initiatives and studies on learning communities, a key concept for de- fining the educational model for many e-learning interventions and about which pages and pages have been written, we will discover that these communities favor a high degree of interaction and communication, but we will not be able to avoid a certain feeling of anarchy and loss of time in most of these collective groups. To use Kantian terms, there are many theses and antitheses, but few syntheses and above all there is still great difficulty in determining who has attained certain training objectives and to what degree. Furthermore, we lack a certain criterion of authority (in the Latin sense of the term auctoritas) which makes it difficult to select the best syntheses of the common task because there is a belief (generally naïve) that in these communities a final synthesis of knowledge per se is produced, when what usually happens is that, when this does occur, each member contributes his/her view of the problem, but neither a conclusion nor a consensus is reached on it. This is so because although e-learning environments "transform the social interaction space, ... a deeper understanding of the 'inside' of the collaborative learning processes is still missing" (Cecez-Kecmanovic \& Webb, 2000). Of course, learning communities, especially when made up of qualified adult individuals, are instruments with high educational capacity thanks to the possibilities of interaction and communication and their potentiality for favoring contexts of critical and active construction of knowledge. However, the problem of learning communities, at least in the shape they have taken in a good part of prior experience, lies in their excessively "democratic" approach. Favoring a cognitive and social presence in these communities is not enough. In order to be able to design, direct, and nurture interaction in a learning community, a strong teaching presence is necessary. This does not have to affect the open and critical nature of these communities; what is more, the key factor for success in these communities will lie in the teacher's ability (as in face-to-face teaching) to create a suitable climate that will favor the setting 
up of a genuine learning community, one that is perfectly monitored and well-constructed (Garrison \& Anderson, 2003, 2005).

Thus, we have contexts, we have interaction models and, of course, technology, but we lack methods for the development of quality training initiatives. A method is nothing more than a guide or instructions as to the road to follow to reach certain objectives. In this case, the method has to be understood in a three-fold sense: first, as the set of instructions and strategies offered to the teacher in order to achieve the learning objectives; second, analogous rules must exist for the correct acquisition of the contents on the part of the student (who should also have a method); finally, since e-leaning favors social knowledge building and social learning is by far the most significant of all those that exist, a method is needed to regulate social interaction with an educational purpose, especially when we are in a "non-natural" context such as that of virtual learning environments.

\section{CONSTRUCTIVISM AS A GOAL, BUT NOT AS A METHOD}

One of the terms most used in relation to e-learning (to the point that its original meaning has become completely lost and it is now used gratuitously) is "constructivism," as a synonym of prestige, careful methodology, and good practice. This expression can be found in essays on methodological approaches or theories for online training, in the explanation of the instructional design of an initiative, in the conception of a learning object or even (surprisingly) to advertise the virtues of a software tool addressed to online training.

The problem is that constructivism is not a method, nor even a theory, but rather an explanatory framework (Coll et al., 2005) which tells us that defacto learning occurs in a social, collective context and is the fruit of construction beyond the solitary consciousness of the individual. Ac- tually, the ideas of Vygotsky (Vyg $\rightleftharpoons$ y, 1979; Vygotsky \& Cole, 1978), those of Brtur (Bruner, $1997,1998)$ and even those of Dewey $(1933,1938)$ form part of an ideological and philosophical context developed during the 20th Century in opposition to the methodic individualism and transcendental philosophies of consciousness that were developed up to the $19^{\text {th }}$ Century and which had their last great exponent in Hegelian idealism. Philosophical approaches in accordance with this presuppose a new type of rationality that replaces an idealist paradigm with another of dialogical, communicative, and social rationality which we can find in key thinkers of the last century such as Gadamer, Apel, and Ortega y Gasset.

Thus, constructivism explains, according to the ideological presuppositions of its time, how knowledge is constructed in the human mind. This does not presuppose the existence of an implicit method, or that this explanatory framework can provide us with this method by itself. In simple terms, thanks to cognitivist and constructivist thinkers, we know that the cognitive process takes place in a certain way, which does not mean that they have told us how to get our students to acquire the competencies and skills we program in a learning initiative. This is the difference between an explanation and a method: knowing what has happened (and even knowing why) and knowing how to make it happen again, adapting it to predetermined learning circumstances.

Therefore we may ask: What does constructivism offer us? What is it good for?

The thesis here defended postulates that constructivism can be considered as a goal for learning, even as a "table of validation" thanks to which we will be able to verify the solidity of the knowledge acquired by our addressees. At most, it could be a guide or perspective for preparing a training methodology, but in no case must we confuse the end with the means that we intend to use for reaching our objectives. Constructivism is thus not valid as a method, and the need to develop a methodology for online training remains pending. 
However, in the name of constructivism, many practices in e-learning have become widespread, practices which, based on the supposed virtues of the training paradigm, entail more than a few difficulties and are to a certain extent responsible for the high failure index of online training initiatives. We now take a look at some of them.

\section{The Excuse of a Student-Focused Model}

Together with expressions such as "constructivist methodology" we often find a reference to the "student-focused model." In many cases this statement is correct, but students end up discovering that it means something completely different from what they expected. In general, placing students at the center of learning is usually an excuse to unload the whole weight of learning on them and propose a self-learning itinerary with as little assistance as possible. Indeed, if students are the protagonists, they are solely responsible for carrying out the learning task. This is the meaning of "occupying the center" in many e-learning initiatives.

A model in which the student occupies the center of the training scenario, far from being a privilege and a stimulus, in many cases ends up being a drawback and gives rise to results contrary to those desired. To show this graphically, the central position of students means that all the elements revolve around them and none of these elements are a point of reference, but rather they all have the student as a reference. This image, which may seem somewhat strange, is disconcerting for many students who are not used to an autonomous style of learning, to setting their own rhythm of learning, and to adapting to the peculiarities of the environment, because the environment never adapts to them.

It is true that this training model adapts perfectly to the peculiarities of self-taught persons with a great ability to turn information into training by themselves. However, most individuals need a figure to act as guide and help them change the information into training thanks to his or her mediation. In many cases, this mediation occurs "among peers" (how many of us have learned, thanks to our classmates what our teachers had not been able to make us understand?) but we must not renounce a teaching figure who, suitably adapted to the context, can perform this mediation.

The students, therefore, do not have to be the center of learning but the goal of this task, since they are the addressees of the training intervention. In any case, the oft-mentioned "center" should be occupied by that element of human mediation that here we call "tutor" and who adapts the training initiative (with all its technological, academic, didactic, and human components) to the peculiarities of each addressee, takes charge of guaranteeing the actual acquisition of the competencies and skills foreseen for the training initiative and is ultimately responsible (often even more so than the student) for attaining the training objectives.

\section{The Existence of a Community is not Enough for Social Learning to Occur}

Another of the presumed virtues of many online training initiatives with a constructivist approach is the guarantee of training success based on community working dynamics. Gathering together in one room a hundred splendid musicians will not make this assembly an orchestra, the same as a set of sailors enlisted on the same ship cannot be considered a crew. For there to be a real community (musical, nautical, sport, or learning) we need much more than a set of related individuals in the same space-time or "virtual" context. Indeed, as Gestalt psychologists affirmed, inspired by the old discussion that Aristotle initiated in his Metaphysics (1028a-1041b), the whole is more than the sum of its parts.

No one will be surprised if we say that the social context is one of the most efficient and common forms of learning, as is shown in the way we acquire knowledge of our native language - without 
the need to enroll in any educational institutionand attain a notable mastery of it. However, when we make a set of persons in a training initiative interact, we have no guarantee that they will form a genuine learning community. Communities of students are artificial societies, and making the "sum of the parts" into a "whole" is frankly something very complex. Thus, obliging students to work in a group does not presuppose that they are going to form a learning community. This is a problem well-known to tutors and experts in virtual group dynamics who, using the same strategies in seemingly analogous groups, often attain completely different learning outcomes, both individually and collectively. Turning a group of students into a learning community is a real art, as is turning a hundred musicians into an orchestra. The former may even be more difficult than the latter, but this is coming from someone who has never directed an orchestra.

The dynamics that are set up in a learning community are complex and require detailed study. There are magnificent works on learning communities (Wenger, 1998a, 1998b) but there is no method capable of guaranteeing that we will be able to reproduce or build an efficient community. Nevertheless, we can affirm that opening up debate and promoting team work is not enough to constitute a learning community and to "construct" a social learning context. A group must have good leadership and be solidly structured so that guidelines for behavior can be developed that in the end will turn this sum of the parts into a whole that functions as an authentic community. In other words, the possibilities for success in the building of learning communities online (or face-to-face; there are no significant differences in this respect) increase when we start from a situation that includes teaching roles that regulate communication flows, establish guidelines and rhythms for learning, and foster the active participation of the members. The construction of learning in a community is a task that is shared not only by each and every one of the students involved, but also includes the tutor or tutors at the head of said community. It is a matter of achieving a dynamic or model that some scholars call socioconstructivist, in which the result of social construction is not the responsibility of the students or the teachers (the model is not focused on the student or the teacher), but rather is the outcome of interaction between learning contents, teaching staff, and students (Barberà, 2006) by means of a design for activities that foment the acquisition of competencies and skills and that have an eminently practical approach that favors this interaction.

\section{Tools Do Not Construct}

The third of the usual practices that can be observed in many initiatives inspired by constructivism is the use of technological tools and methods that are posited as constructivist per se. It is well known that constructivism and especially social constructionism is the theoretical reference model for many developers of software for online learning, especially open source. Possibly the best-known system of this type for course management, Moodle (http://moodle.org), confesses on its main page that its philosophy is "social constructionist pedagogy" based on four underlying concepts: constructivism, constructionism, social constructivism, and connected and separate (Moodle, 2007). The creator of this instrument, Martin Dougiamas, has said that his reference model when designing Moodle was the analysis of learning communities based on constructivism and social constructionism (Dougiamas \& Taylor, 2003).

However, the use of Moodle or any other elearning tool does not guarantee social construction, nor does it foment the achievement of certain objectives. The intentionality of the person who constructs a tool has nothing to do with the use that users may make of it and the corresponding outcomes. Was Alfred Nobel responsible for the belligerent use of dynamite, a compound origi- 
nally intended to prevent the constant accidents in mines owing to the instability of nitroglycerine? Likewise, the tools that we use may be more or less suited to the aims and training strategies of our activities, but in themselves they do not give any guarantee whatsoever of constructivist learning. What is more, it could be said that the type of tool we use is practically irrelevant (as long as it fulfills certain minimum conditions) compared to the importance of a good instructional design, a correct training strategy, and a good human team to head the teaching-learning process.

Let us then assume that a quality online training initiative has to have as its goal that the students should achieve significant, active, learning constructed within a social context whenever possible in the midst of a learning community. However, in order to achieve this objective, we have to avoid three major obstacles which, like a tree in front of us, can prevent us from seeing the forest. On the one hand, the affirmation of a student-focused model does not at all guarantee a construction (much less a social construction) of knowledge; on the contrary, it can even hinder it. On the other hand, we often observe a confusion between group work and learning community, or between group and community. Finally, we have been able to show that the use of certain tools does not at all condition the social knowledge building, because this depends on the modalities of interaction that occur in the dynamics of training activities; thus, they have to do with humans, not with machines.

In short, learning (in e-learning or in conventional environments) is the product of social interaction which as such has rules, roles, and defined structures. To extract all its potentialities, it must be correctly moderated and led by someone with a professionally well-defined teaching profile, who plays a particularly important role in online training and on whom the success of our initiative largely depends.
The methodology of our online training initiatives must therefore revolve around the central and catalyzing figure of the tutor.

\section{IN SEARCH OF A GROUNDWORK FOR THE METHOD}

\section{Contributions from Greek $\sqrt{\bar{\equiv}}$ deia}

Taking into account the starting supposition of these pages, to wit, the importance of monitoring learning through a specialized professional profile, to which the major share of the training methodology will fall, it is evident that we are not looking at the traditional teaching figure, at least as understood in our current school systems. It is thus a matter of a professional whose main mission is not to emit knowledge but rather to guarantee that it reaches the addressees, in an active, participative, and significant context. In our opinion, a large part of the success or failure of online training initiatives will depend on whether or not we have this type of professional, suitably inserted in a solid and well-constructed context of training planning.

The big question now is as follows: Has there ever been in the history of education a professional profile of such characteristics? Do we have any model that can serve as a reference, and from which we can develop the role that corresponds to our quality teacher in e-learning initiatives?

Our answer is clearly affirmative. Indeed, in Ancient Greece we can find "teaching" models whose characteristics, despite forming part of a context so different from today's, which is not even homogeneous, are extraordinarily interesting for the task at hand, which is none other than designing a suitable teaching profile for online training methodology. Briefly, and by way of example, below we give the "professional" profile of these personages that will serve as inspiration for the construction of our online teacher and his or her methodology. 


\section{The Mentor as Teacher of the Homeric Hero}

One of the first testimonies of the teacher-disciple relationship and thus of interaction between teaching profiles and pupils in a learning context that we know of in western culture has its source in Greek mythology and the Homeric epic. The epic heroes acquire their greatness both from their ancestry and, what is even more interesting, from the presence and importance of their teachers, who not only educate them and prepare them to face the hazards of the heroic life, but even carry out a constant follow-up of their disciple's actions, intervening when they are most needed.

Achilles was taught by no less than the centaur Cheiron and by his mother the goddess Thetis; the latter intervened even at the moment when the hero doubted whether he should or should not go to the Trojan War, helping him to weigh his decision. Indeed, Achilles had to choose between two ways of living and dying. On the one hand, if he decided to stay he would marry, have children and grow old as a king and after his death his descendants would remember him. On the other hand, if he decided to go to war, he would die young without descendants, but the whole of humanity would admire his deeds forever. Everyone knows the result of his choice. Odysseus, for his part, received the permanent guidance of the goddess Athena, who appeared to him on several occasions to advise him, such as on his return to Ithaca, when she changed him into a beggar and proposed a plan to put an end to the suitors that were harassing Penelope and ruining his property.

In these cases we encounter figures that appear in the life of the Homeric heroes, who are undoubtedly of greater rank and importance than their disciples, but who do not outshine the actions of their pupils. Rather, the opposite: they extol them by placing them in circumstances in which they will be able to come out with flying colors, magnified by their bravery and preparation.
There is no room for doubt that the prominence goes not to the teacher but to the disciple, but neither can it be denied that the constant presence of the teacher, the security that it gives the hero to know that someone is watching over him and appears when most needed, even placing him before complex situations from which he must extract new teachings, is a model of training and permanent tutoring that is characteristic of the Greek paideía.

However, the most characteristic example from which we can extract greater conclusions is that of the relationship between Mentor and Telemachus in the Odyssey.

According to Homer's Odyssey, when Odysseus left Ithaca and was away fighting in the Trojan War, his son Telemachus was just an infant. So Odysseus entrusted Mentor with the care of Telemachus and the entire royal household until he came back 20 years later. Although Mentor is not a main character in Homer's epic poem, he represents wisdom, trust, counsel, teaching, protection, challenge, encouragement, and so on. (Anderson \& Shannon, 1995; Carruthers, 1993). Mentor's authority was so important to Telemachus than even the goddess Athena took the figure of Mentor to persuade the hero's son to search for his father.

The role of Mentor instructing Telemachus is not quite clear in Homer's poem, and this is one of the most interesting questions about the matter. Never mind if Mentor (or Athena) is the real "teacher" of Odysseus' son. It is strange that Mentor is mentioned just a few times in the Odyssey and we do not know how he "really" instructed Telemachus. The only important thing is that Telemachus achieved enough maturity to know how to face Penelope's suitors and help his father to complete the final revenge: he became a man with the help of an old person whose mission was to remain in the dark, "tutoring" Telemachus' steps, not helping him but following his tracks at a certain distance, because no one can drive the fate of a man except himself. In fact, the unde- 
fined, secondary but crucial role of Mentor has not changed so much with regard to the excellent "Mentors" of e-learning students nowadays.

Etymologically, "mentor" produced "monitor" in Latin. The verb "maneo" (to show, to indicate) comes from the Indo-European *man (to think, to know). So Homer's character Mentor is an anthropomorphization of this idea: wisdom (Little, 1990), thought, knowledge (and consequently know-how), personified by an old man whose purpose is to transmit these skills.

In the figure of old Mentor we find, then, an excellent personification of the role that the online training teaching profile should play. From a supporting role, yielding prominence to the disciple, he nevertheless invites the latter to act, to solve problems and to learn through action. Learning, according to the principles of Greek paideía, was not based on acquiring theoretical knowledge or specific practical skills, but had to be oriented towards achieving areté, that which the Romans subsequently translated as virtus and which, erroneously, through Christianity, reached the West as "virtue." In Homeric times, areté was related to the values peculiar to heroes, to noble warriors and was a mixture of moral and martial ideals. Later, in the classical age, paideía transformed the meaning of areté, which now acquired a more humanist and political approach. Then, "excellence" (a more correct translation of the Greek term than "virtue") consisted of the acquisition of all the values that make a man a citizen, a being capable of moving with ease in the polis and actively participating in the life of the city. Thus, for the Greeks, education (understood as an activity oriented towards practice and citizenship, and not as a simple learning of contents) is the key to the evolution of a civilization, and linked from its origins to the heroic epic until its splendor in Athenian democracy, it appears as the motor behind Greek culture. Such was the importance of education (of this type of education) in Ancient Greece (Jaeger, 1945).

\section{The Education of Man as a Citizen: The Sophists and Socrates}

Towards the second half of the 5th Century B.C. and especially in the last quarter, a real revolution occurred in the way education was conceived of in Greece, to be precise, in Athens. The economic, social, and political changes that occurred in the city favored the appearance of new social needs and a fairly widespread demand for education far above what had until then been received in the family sphere, which only reached a certain level in the higher social strata. This growing demand favored the arrival in Athens of the Sophists, who unleashed a whole revolution in the way of conceiving education and, of course, aroused great controversy which, even now, has still not been analyzed with sufficient neutrality.

Here it is not our intention to study what the arrival of the Sophists in Athens meant for education. There are several essays (in general fairly critical of the work of these thinkers) which can be referred to for a more detailed analysis, ranging from the more generic ones by William K.C. Guthrie (Guthrie, 1971), Mario Untersteiner (Untersteiner, 1954), and Jacqueline de Romilly (Romilly, 1992) to those that deal with specific aspects such as their role in Greek Rhetoric (Kennedy, 1963). On the other hand, it is our intention to call attention to a conception of education in which both the Sophists and Socrates coincide, and which has to do with the active social and political nature of education. We will also deal with some of the differences that may be interesting for our purpose.

The same as occurred in Homeric times, the main purpose of education for the Sophists and Socrates was none other than attaining excellence, areté. However, although still maintaining a certain competitive view of excellence (i.e., an approach according to which areté is shown in superiority over other men owing to its origin in the noble and warrior class, as we have seen in the previous section), the meaning of the term 
underwent a significant variation. In this age areté was linked to social and political success and, therefore, the main objective of teaching was none other than to form good citizens, aware, as the Greeks of that age were, of the importance of social and political interaction. Thus, learning was not something erudite and private, but had to have a social and public usefulness; in a certain sense, moreover, it was an emancipating task because it guaranteed success and social advancement and what is perhaps more important, the usefulness of learning was immediately perceived in its application to the social context.

What Socrates and the Sophists did disagree on was the possibility of being able to teach areté. According to Socrates it was more a quality of the soul that one did or did not have and which, at most, the "teacher" could help to find inside the disciple through the Socratic dialogical method known as mayeutics. The Sophists, however, considered that it was possible to teach, in an orderly and structured way, everything required to be an excellent citizen; such teaching, of course, included, among other things, rhetoric, because one of the keys to social success in a civilization such as the Greek one entailed admiration and respect for those with a beautiful and persuasive diction, those who today we would call "charismatic." This, of course, could lead us into a debate as to whether charisma can be taught or not, and so we would return to the polemics between the Sophists and Socrates, but let us leave this question for the moment.

Protagoras, according to Plato's dialogue of the same name, used the myth of Prometheus to show us that all humans have political virtue by order of Zeus himself, who even ordered that all men should cultivate it and practice it under penalty of being exiled from the city (Plato, Protagoras, 320d-322d). Without going into whether political virtue can be taught or not, the important thing is that education is defined as an activity oriented towards the social sphere and above all to the interaction of citizens in a political context in which the command of language and rhetoric plays a major role. The teaching-learning relationship is an eminently linguistic activity.

As regards Socrates and his particular method of teaching, there are some differential elements that we would like to call attention to (leaving aside the polemics with the Sophists for the moment). Socratic mayeutics is a method based on dialogue, on the art of questioning the disciple so that the latter will be able to find his own answers. Hence, according to Plato's old teacher, the teacher does not really teach the disciple anything but merely helps him to find for himself the answers which, really, were already inside him.

What is really interesting in this methodology is that the student is the one who answers the questions and solves the problems. The teacher's method consists of knowing how to ask and how to encourage the disciple to look for the answers. Really, he or she is more a stimulus and a guide than an open book in which to find the solution to problems. Even if this is true (and probably it is), the virtue of the teacher consists of making the student believe that she has found for himself the answer to the questions posed. It is a methodology that gives prominence to the student without the teacher disappearing; the latter is always there, ready to orient and advise.

Thus, the Socratic method can be defined as dialogical, process-oriented (we understand learning as a process), and proactive. These characteristics are undoubtedly major elements for an online training methodology on which to construct the professional profile of our e-learning teacher.

Furthermore, sophistry has revealed that education has an eminently social nature, and that it is precisely in this context where learning gains meaning, beyond mere erudition without specific usefulness. These elements are equally important when constructing an appropriate method for our new training. 


\section{CONCLUSION}

What sense is there in posing a reflection of the concept of paideia in Ancient Greece in order to develop a methodology suited to online training? As has been seen at the beginning of this chapter, most e-learning initiatives are set in motion without having a clearly defined method or a strategy suited to the peculiarities of this type of training.

Moreover, there seems to be a more or less widespread trend to accept constructivism as an explanatory framework or theoretical presupposition. However, constructivism is a cognitive theory rather than a method and perhaps this confusion lies at the bottom of many serious errors related to training paradigms fore-learning. Thus, if constructivism indicates to us a desideratum, a goal, but is not a method in itself, the need remains to set up a path on which to trace the route of learning in an interaction framework as peculiar as the one corresponding to online training.

In short, all theoretical reflection on this type of training revolves around what should be done, but there is very little effective orientation to indicate how to achieve what we are supposed to do.

After analyzing the different conceptions of education throughout history, we feel that the Greek paideía model is perfectly suited both to the presuppositions of the commonly accepted theoretical framework and to a more realistic (and in a certain sense, "classical") position, according to which a teaching profile is necessary in order to guarantee the success of a training initiative.

The model from Ancient Greece shares with us the idea that training is a task that falls to the subject being trained, but which is not achieved alone and without the presence of someone who, although remaining in the shadows, will always appear when needed and will be capable of showing us the road to knowledge. This knowledge, however, is not understood as a simple acquisition of contents but rather will be developed in capabilities, competencies, and skills which only make sense if put into practice and therefore are learned along the way. This action, which is the result of knowledge, is revealed in a social context, a context in which new knowledge is produced as the result of the action and interaction of the subjects. Knowledge is, then, the fruit of a social environment. Finally, dialogue and language are the basic elements in the quest for learning, since this is no more than a continual process of questions and answers, answers that lead to new questions...

The purpose of these pages was not, then, to develop a method for online training based on the activity of the tutor as a catalyst in the teachinglearning relationship, as has been done in previous studies (Seoane Pardo \& García Peñalvo, 2006; Seoane Pardo, García Peñalvo, Bosom Nieto, Fernández Recio, \& Hernández Tovar, 2006). On this occasion, on the contrary, we opted to illustrate the groundwork on which to build this method, starting from a model with a long tradition and which, by the way, is to be found in the very foundations of western civilization.

\section{FUTURE RESEARCH DIRECTIONS}

The philosophical and epistemological reflections contained in this chapter are part of a more ambitious research concerning a new methodology for online training, especially a methodology for training "online teachers" or "tutors" (also known as "facilitators" or "e-facilitators" in other contexts).

These considerations, among with the main hypotheses of that methodology, are being tested in several initiatives developed by the University of Salamanca that are being addressed to different kind of users with completely different learning contexts and with remarkable success in all the various scenarios where this methodology has been proved.

Most of the theories and even case studies related to methodology and didactics in e-learn- 
ing contexts analyze the learning contexts and how students learn in these initiatives, simply explaining the scenario or offering a sum of suggestions to improve the learning experience. But still persists the need of a real teaching model for e-learning activities, because teaching roles are still fundamental to let trainees achieve the desired goals, skills, and competences required for any learning activity.

Thus the main challenge for the near future is the definition of a complete methodology for training teachers specifically adapted to online contexts, among with the clear definition of their skills and competences. These studies, actually being proved in real learning contexts, will be completed with several "user manuals" for online teachers, students, learning content designers, and instructional designers, all of them adjusted to a rigorous quality framework that must preside the whole process of every learning activity that aspire to deserve the qualifying of excellence.

\section{ACKNOWLEDGMENT}

This work has been partly financed by the Ministry of Education and Science (Spain), KEOPS Project (TSI2005-00960).

\section{REFERENCES}

Anderson, E.M., \& Shannon, A.L.(1995). Towards a conceptualization of mentoring. In T. Kerry \& A.S. Mayes (Eds.), Issues in mentoring. London: A.S. Routledge.

Barberà, E. (2006). Los fundamentos teóricos de la tutoría presencial y en línea: Una perspectiva socio-constructivista. In J.A. Jerónimo Montes \& E. Aguilar Rodríguez (Eds.), Educación en red y tutoría en línea (pp. 161-180). Mexico: UNAM FES-Z.
Bruner, J. (1997). La educación, puerta de la cultura. Madrid, Spain: Visor.

Bruner, J. (1998). Desarrollo cognitivo y educación. Madrid, Spain: Morata.

Carruthers, J. (1993). The principles and practices of mentoring. In B.J. Caldwell \& E.M.A. Carter (Eds.), The return of the mentor: Strategies for workplace learning. London: Falmer Press.

Cecez-Kecmanovic, D., \& Webb, C. (2000). Towards a communicative model of collaborative Web-mediatic learning. Australian Journal of Educational Technology, 16(1), 73-85.

Coll, C., Martín, E., Mauri, T., Miras, M Onrubia, J., Solé, I., et al. (2005). El construct $\overline{\overline{\bar{\sigma}}}$ b en el aula Vol. 111 (15th ed.). Barcelona: Graó.

Dewey, J. (1933). How we think. Boston, MA: Heath.

Dewey, J.(1938). Experience and education. New York: Macmillan.

Dougiamas, M., \& Taylor, P.C. (2003). Moodle: Using learning communities to create an open source course management system. Paper presented at the Proceedings of the EDMEDIA 2003 Conference, Honolulu, Hawaii.

Garrison,D.R., \& Anderson, T.(2003).E-learning in the 21 $1^{\text {st }}$ century: A framework for research and practice. London, New York: RoutledgeFalmer.

Guthrie, W.K.C. (1971). The sophists. London: Cambridge University Press.

Jaeger, W. (1945). Paideia: The ideals of Greek culture (G. Highet, Trans.). New York: Oxford University Press.

Kennedy, G.A. (1963). The art of persuasion in Greece. Princeton, NJ: Princeton University Press.

Little, J.W. (1990). the social organisatzon of teaching. In Review of 
Research in Education. Washington, DC: American Educational Research Association.

Moodle. (2007). Philosophy. Retrieved October 17, 2007, from http://docs.moodle.org/en/Philosophy

Romilly, J.d. (1992). The great sophists in Periclean Athens. Oxford, UK, New York: Clarendon Press, Oxford University Press.

Seoane, A.M., García, F.J., Bosom, Á., Fernández, E., \& Hernández, M. J. (in press). Online tutoring methodology approach. International Journal of Continuing Engineering Education and Life-Long Learning (IJCEELL), 17(6) $\equiv$

Seoane Pardo, A.M., \& García Peñalvo, F.J. (2006). Determining quality for online Activities. Methodology and training of online tutors as a challenge for achieving the excellence. WSEAS Transactions on Advances in Engineering Education, 3(9), 823-830.

Seoane Pardo, A.M., García Peñalvo, F.J., Bosom Nieto, Á., Fernández Recio, E., \& Hernández Tovar, M.J. (2006). Tutoring online as quality guarantee on e-learning-based lifelong learning. Definition, modalities, methodology, competences and skills (CEUR Workshop Proceedings). Virtual Campus 2006. Selected and Extended Papers, 186, 41-55.

Untersteiner, M. (1954). The sophists. New York: Philosophical Library.

$\equiv$ ksky,L.(1979). El desarrollo de los procesos

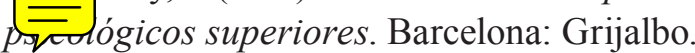

Vygotsky, L.S., \& Cole, M. (1978). Mind in society: The development of higher psychological processes. Cambridge, MA: Harvard University Press.

Wenger, E. (1998a). Communities of practice. Learning as a social system. Retrieved October 17, 2007, from http://www.co-i-l.com/coil/knowledge-garden/cop/lss.shtml
Wenger, E. (1998b). Communities of practice. Learning, meaning and identity. Cambridge: Cambridge University Press.

\section{ADDITIONAL READINGS}

Anagnostopoulos, D., Basmadjian, K.G., \& McCrory, R.S. (2005). The decentered teacher and the construction of social space in the virtual classroom. Teachers College Record, 107(8), 1699-1729.

Ardizzone, P., \& Rivoltella, P.C. (2003). Didattiche per l'elearning. Metodi e strumenti per l'innovazione dell'insegnamento universitario. Roma: Carocci editore.

Bereiter, C., Scardamalia, M., Cassells, C., \& Hewitt, J. (1997). Postmodernism, knowledge building, and elementary science [Special Issue: Science]. Elementary School Journal, 97(4), 329-340.

Jonassen, D.H., Carr, C., \& Yueh, H.-P. (1998). Computers as mindtools for engaging learners in critical thinking. TechTrends, 43(2), 24-32.

Maldonado, T. (1994). Lo real y lo virtual. Barcelona: Gedisa.

Marcelo, C., Puente, D., Ballesteros, M.A., \& Palazón, A. (2002). E-learning-teleformación. Diseño, Desarrolloy Evaluación de la Formación a través de Internet. Barcelona: Gestión 2000.

Ruipérez, G. (2003). Educación Virtual y eLearning ( $1^{\mathrm{a}}$ ed.). Madrid: Fundación Auna.

Scardamalia, M. (2002). Collective cognitive responsibility for the advancement of knowledge. In B. Smith (Ed.), Liberal education in a knowledge society (pp. 67-98). Chicago: Open Court.

Scardamalia, M., \& Bereiter, C. (2003). Knowledge building environments: Extending the limits of the possible in education and knowledge work. 
In A. DiStefano, K.E. Rudestam \& R. Silverman (Eds.), Encyclopedia of distributed learning. Thousand Oaks, CA: Sage Publications.

Scardamalia, M., \& Bereiter f. (2003). Knowledge building. In Encyc $\overline{\bar{\nu}}_{\text {ia }}$ of Education ( $2^{\mathrm{a}}$ ed.) (pp. 1370-1373). New York: Macmillan Reference.

Vygotsky, L.S., \& Kozulin, A. (1986). Thought and language (Rev. ed.). Cambridge, MA: MIT Press. 